This item was submitted to Loughborough's Research Repository by the author.

Items in Figshare are protected by copyright, with all rights reserved, unless otherwise indicated.

\title{
A supersonic underwater discharge as a high-power ultrasound source
}

PLEASE CITE THE PUBLISHED VERSION

https://doi.org/10.1109/TUFFC.2021.3054588

PUBLISHER

IEEE

VERSION

AM (Accepted Manuscript)

\section{PUBLISHER STATEMENT}

Personal use of this material is permitted. Permission from IEEE must be obtained for all other uses, in any current or future media, including reprinting/republishing this material for advertising or promotional purposes, creating new collective works, for resale or redistribution to servers or lists, or reuse of any copyrighted component of this work in other works.

\section{LICENCE}

All Rights Reserved

\section{REPOSITORY RECORD}

Stobbs, Jessica, Bucur Novac, Peter Senior, Matthew Woodyard, and Paul Lepper. 2021. "A Supersonic Underwater Discharge as a High-power Ultrasound Source”. Loughborough University.

https://hdl.handle.net/2134/14130254.v1. 


\title{
A Supersonic Underwater Discharge as a High-Power Ultrasound Source
}

\author{
Jessica M. Stobbs, Student Member, IEEE, Bucur M. Novac, Senior Member, IEEE, Peter Senior, Member, IEEE, \\ Matthew Woodyard, Student Member, IEEE, and Paul Lepper
}

\begin{abstract}
A supersonic underwater discharge system, driven by a pulsed power generator with $235 \mathrm{~ns}$ voltage rise time was developed to be used as a powerful ultrasound source. The paper presents details of the system's components and the various diagnostic methods used, together with the main findings obtained during the first experimental campaign. The system generated a peak pressure of $184 \mathrm{kPa}$ at $1 \mathrm{~m}$ distance, with an efficiency of energy conversion from electrical to acoustic estimated as $0.8 \%$. The pressure profile was found to display a resemblance to the radiation pattern generated by a dipole antenna. Using an ultrahigh speed camera, a study of the inter-electrode discharge revealed details of the pre-breakdown streamer dynamics and an estimate for the lifetime of the post-breakdown plasma column. The way forward includes testing the system at a very high repetition rate.
\end{abstract}

Index Terms - Ultrasound, pulsed power, plasma, streamer, pulsed pressure

\section{INTRODUCTION}

$\mathrm{H}$ IGH-power underwater electric discharges have been fundamental to pulsed power technology for decades. Namely in pulsed power switching, but also in a large number of industrial applications including: underwater welding and electro-hydraulic forming [1], shockwave generation for industrial sludge treatment, removal of foreign deposits from pipe walls or materials fragmentation, separation, reduction and recycling [2-4], for mining applications such as blasting [5] and drilling [6], for demolition [6], wastewater treatment and sterilization [7], bio-fouling control [8], removal of algae [9], as well as special bio-medical applications. A number of these applications are well described in a book dedicated to the pulsed electric breakdown of liquid phenomena [10].

The present paper is related to using electrical discharges to produce high power acoustic waves with large amplitudes, short duration and wideband frequency. Such acoustic waves, termed high-power ultrasound (HPU) [11], have often been used in maritime applications [12-13]. There are two main regimes by which HPU can be generated: subsonic (by oscillating bubblebased mechanism) and supersonic (by streamer-based mechanism).

The subsonic technique is achieved by a relatively slow (tens of microseconds) application of a high-voltage across electrodes immersed in water, resulting in a Joule-heated creation of a gas bubble within which electrical breakdown of the water gap occurs. The discharge-driven periodic expansion and collapse of the bubble produces HPU by virtue of the bubble's surface performing the role of the membrane in a loudspeaker. A single discharge may produce several oscillations over hundreds of microseconds, up to tens of milliseconds, depending on the water conductivity and the electric field strength applied. Recently, more attention has been given to understanding the physics of subsonic HPU sources [13-17]. Owing to the long discharge period it is not practical to achieve a high pulse repetition frequency (PRF) operation with subsonic discharges.

By contrast, the supersonic technique requires a very fast voltage impulse, with a rise time of tens to hundreds of nanoseconds. This impulse is normally applied to an electrode geometry specifically designed to generate an intense and highly inhomogeneous electric field distribution, such as pointplane. Key processes involved in the supersonic electric breakdown of water are thus facilitated: field emission and field ionization, field acceleration and impact ionization. Through a combination of these processes, conducting ionization paths known as streamers propagate across the electrode gap with a tree-like structure. Upon the successful connection of the electrodes by an ionized path, current is mainly directed through it, forming a highly conductive plasma channel. The corresponding Joule energy is delivered to the surrounding water, causing the water to violently expand and generate a powerful shock wave.

The HPU generated under these circumstances is different from that produced with the bubble-based subsonic technique, as the energy is deposited much more rapidly, resulting in a much shorter duration (microseconds) acoustic pulse with a considerably wider bandwidth (up to a few $\mathrm{MHz}$ ).

The literature surrounding supersonic pre-breakdown (streamer) phenomena has been comprehensively reviewed in [18] and the physics of the fast breakdown process in [19-20]. However, the application of these processes to generate HPU remains an unexplored field, to the best of the authors' knowledge.

The present paper is dedicated to the development of a supersonic HPU source using a bespoke pulsed power generator. The major interest in developing this type of source is the unique capability to drive this low-energy system at very high PRF. There are applications in the bio-medical domain 


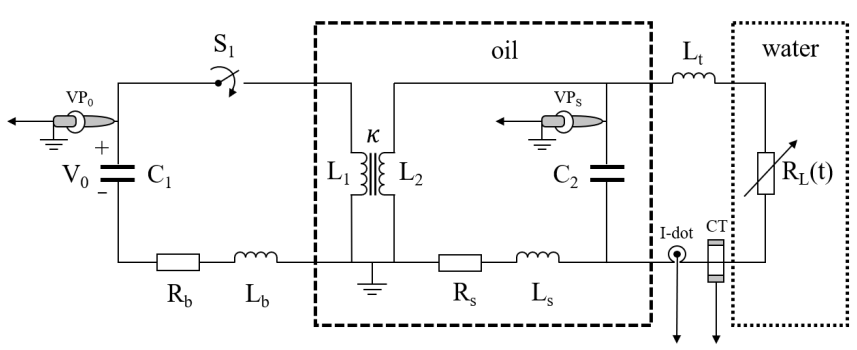

Fig. 1. Equivalent electric scheme of the HPU system based on a fast-pulsed power generator. See text for details.

[21-22], food processing technology [23] and geological survey that require a HPU source with such characteristics. The system described, although only demonstrated in single-shot mode in the present work, was therefore designed specifically for future $1 \mathrm{kHz}$ PRF operation.

The structure of the paper is presented below. Section 2 describes the pulsed power generator, the electrodes, and the practical arrangement in a laboratory water tank. Diagnostic instrumentation, and a technique for the synchronization of their outputs are also presented in detail. Section 3 presents the main findings, and section 4 comprises the conclusions along with a plan for future development.

\section{PRACTICAL ARRANGEMENT}

\section{A. Pulsed power generator}

The main requirements for the design of the pulsed power generator were to produce a $100 \mathrm{kV}$ output and to operate at a PRF of $1 \mathrm{kHz}$. In a preliminary phase of this research a Tesla transformer-based generator, using a closing switch based on a corona stabilized closing switch was successfully tested up to $1 \mathrm{kHz}$ PRF [24].

The present work is based on an improved HPU system, with the electrical scheme of this faster $235 \mathrm{~ns}$ rise-time generator presented in Fig. 1. A low-inductance capacitor type 37331 (General Atomics [25]) capable of operating at $1 \mathrm{kHz}$ PRF and having a capacitance $\mathrm{C}_{1}=153 \mathrm{nF}$ is mounted in the primary winding circuit of a magnetic core transformer. For single-shot operation, the closing switch ( $\mathrm{S}_{1}$ in Fig. 1$)$ is a trigatron type SG-101M-75C (R. E. Beverly III \& Associates [26]), triggered with a trigger head pulse transformer type THD-02B-02. The pulse transformer is controlled by a trigger generator type PG103D4-02a via a 20-m fiber optic isolation link. For single-shot operation at a charging voltage of $\mathrm{V}_{0}=12 \mathrm{kV}$, the trigatron operates pressurized with 1 bar pressure $\mathrm{N}_{2}$. In these conditions and including all components, the primary winding circuit has a total equivalent resistance of $R_{b}=122$

inductance of $\mathrm{L}_{b}=200 \mathrm{nH}$. The transformer, which will be described in detail elsewhere [27], has a turn ratio of 1:12 with a single-turn primary winding made from thin copper strip having a self-inductance $\mathrm{L}_{1}=5$ and a secondary winding of 12 turns made from a round copper conductor $2 \mathrm{~mm}$ in diameter mounted on a conically shaped coil former and having a selfinductance $\mathrm{L}_{2}=709$ The transformer core is made from Metglas ${ }^{\circledR}$ type AMCC367S [28], which achieves a magnetic coupling coefficient of $\mathrm{k}=0.99$. The transformer is mounted inside a small-size plastic oil tank together with the HV capacitive load $\mathrm{C}_{2}=1.1 \mathrm{nF}$ containing 16 identical TDK UHV$3 \mathrm{~A} 4 \mathrm{nF} / 20 \mathrm{kV}$ ceramic capacitors mounted as two parallel connected stacks, each stack having eight series connected $4 \mathrm{nF}$ units. The total equivalent resistance of the secondary winding circuit is $R_{s}=10$, with the total leakage self-inductance being $\mathrm{L}_{\mathrm{s}}=0.8$

\section{B. Underwater discharge electrodes and their ancillary equipment}

The discharge electrodes are formed of a pin-plane pair, with the plane taking the form of a hemisphere, $60 \mathrm{~mm}$ in diameter, the cylindrical-conical pin having an outer diameter of $5.8 \mathrm{~mm}$ and a tip radius of about 500 For high PRF testing, the electrodes will be manufactured from copper or sintered $\mathrm{Cu}-\mathrm{W}$. However, for convenience, in the single-shot experiments reported here the hemisphere was made from brass and the pin electrodes from stainless steel. The electrodes were coaxially mounted at an adjustable distance inside a watertight acrylic tube filled with deionized water. It was experimentally demonstrated that, for minimizing the Joule losses during the pre-breakdown phase, the electrodes must be covered as much as possible with an insulating material to increase the underwater assembly total equivalent resistance. This requirement proved to be difficult to implement in practice. During the preliminary phase of this research, the most significant issues observed after operating with long bursts at a high PRF were (see Fig. 2) were:

- unwanted electric breakdown at the insulator-metalwater triple point

- destruction of insulators caused by strong shock waves The design of the pin electrode used for the single-shot operation during this stage of the research features a threaded head, which allows for interchanging the electrode to investigate alternative geometries and replacing a damaged head without disassembly of the entire electrode support system. It does however leave a small metallic area uncovered at the interface between the electrode and its support. For increasing the efficiency while operating the system using freshwater, this area had to be covered.

The solution to minimize damage to the hemisphere electrode insulation was to cover less of its surface (in close proximity to the plasma discharge) with epoxy resin, while also implementing a small angle between the insulator and the metal, to tackle the triple point field enhancement.

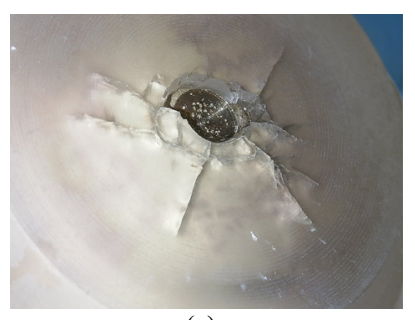

(a)

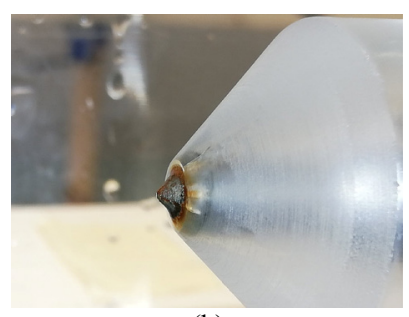

(b)
Fig. 2. Extent of damage caused to electrode insulation by shock waves and intense electric fields: a) hemisphere electrode with cracks, b) pin electrode with deposits due to chemical reaction near triple point and shock wave damage. 


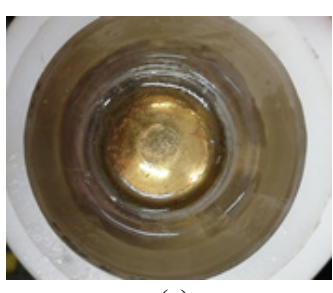

(a)

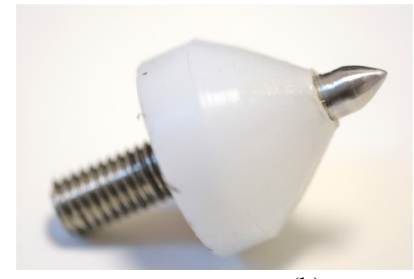

(b)
Fig. 3. Electrodes successfully used during the present work. a) hemisphere electrode b) pin electrode

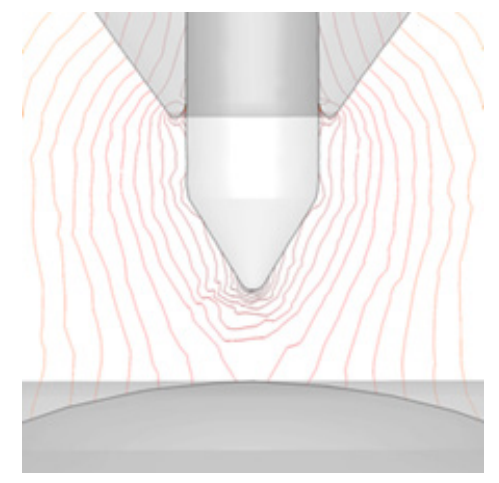

Fig. 4. The electric field distribution produced by the pair of electrodes presented in Fig. 3, when mounted $4 \mathrm{~mm}$ apart. The prediction is made using the CST software [29]: for $1 \mathrm{~V}$ applied on the pin electrode, a peak field of $1000 \mathrm{~V} / \mathrm{m}$ is generated.

Fig. 3 show the pair of electrodes used in the present work and Fig. 4 presents the electric field distribution predicted by the CST software [29]: for $1 \mathrm{~V}$ applied to the pin for an interelectrode gap of $4 \mathrm{~mm}$, the peak field generated under these circumstances reaches $10 \mathrm{~V} / \mathrm{cm}$.

For the purpose of connecting the electrodes to the generator via a (several meter) long transmission line, a HV 50 coaxial cable was not suitable as its characteristic capacitance (about $100 \mathrm{pF} / \mathrm{m}$ ) would introduce a capacitance into the circuit comparable to $C_{2}$. Therefore, two flexible $\mathrm{HV}$ cables were used: the core of a $150 \mathrm{kV}$ coaxial cable type 212A [30] connecting the pin electrode to the HV terminal and a $40 \mathrm{kV}$ cable type 167-9180 [31], connecting the hemisphere to ground. Tests performed during the preliminary phase of this research demonstrated that for most efficient operation of the HPU source, the pin should be positively charged. Fig. 5 presents the experimental arrangement used for testing the HPU source, with an acrylic tube assembly containing the electrodes and filled with deionized water immersed for testing into the $1.5 \mathrm{~m}^{3}$ plastic water tank with dimensions $(\mathrm{x}, \mathrm{y}, \mathrm{z}) 1.25 \mathrm{~m} \mathrm{x} 1.68 \mathrm{~m} \mathrm{x}$ $0.8 \mathrm{~m}$.

During the present preliminary testing, many hundreds of shots were fired in single-shot mode. Some erosion to the electrodes was observed, but at $4 \mathrm{~mm}$ electrode separation this did not affect the reliability of discharge.

\section{Diagnostics}

\section{1) Electrical}

i) Voltage: two voltage probes were used (VP in Fig. 1).

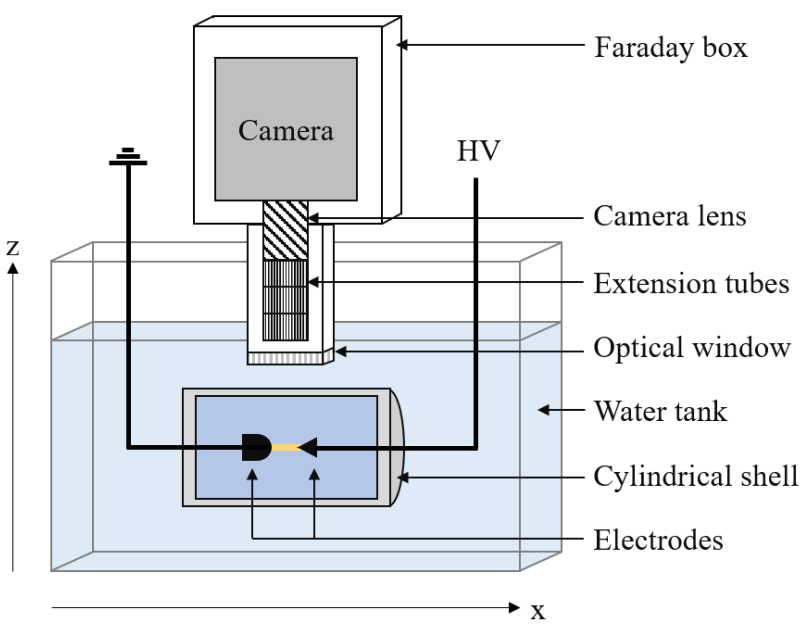

(a)

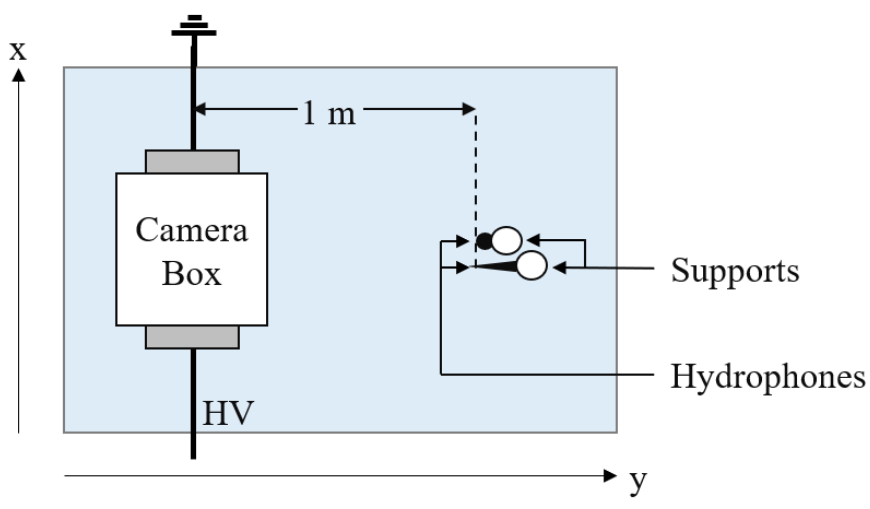

(b)

Fig. 5. Experimental arrangement at the water tank (not to scale). a) $x-z$ plane view b) $x-y$ plane view. See text for details.

$\mathrm{VP}_{0}$ is a type PVM-1 probe [32] used for DC measurements, while $\mathrm{VP}_{\mathrm{S}}$ is a type PVM-100 probe, capable of measuring a peak of $150 \mathrm{kV}$ with $90 \mathrm{MHz}$ bandwidth [32].

ii) Current: two current transformers (CT in Fig 1) type 2877 [33] (peak current $100 \mathrm{~A}$, bandwidth $200 \mathrm{MHz}$ ) were installed as a pair, to provide both a positive and a negative output, allowing for the identification and removal of unwanted capacitive coupling. As the peak plasma current can reach values in excess of $1 \mathrm{kA}$, this exceeds the capability of the above-mentioned transducer. In order to safely use the current transducers, the HV cable attached to ground was connected to an assembly made of 12 short, parallel, connected wires and the two current probes were installed on a single wire, thus each measuring about $1 / 12$ of the total current. As the currents are not exactly evenly distributed through the 12 wires, the output of these probes was separately calibrated using two, lower frequency bandwidth, type 410 current monitors [33], mounted directly on the HV cable attached to ground. 
iii) $d I / d t$ : a simple magnetic pick-up probe, calibrated as an I-dot probe (see Fig. 1), was mounted inside a small helical coil made from the HV cable attached to ground.

iv) Voltage across electrodes: the $V P_{S}$ probe measures the voltage across $\mathrm{C}_{2}$, which can be written as:

$$
=-+
$$

where $L_{t}$ is the self-inductance of the HV transmission line, $R_{L}$ is the time dependent equivalent resistance of the load and $I_{L}$ is the current flowing through the load circuit. During an experiment $R_{L}$ varies with many orders of magnitude while the voltage $V_{L}$ across the electrodes:

$=$

is important for calculating the Joule energy. As $V P_{S}, I_{L}$ and - are all measured by specific probes, the instantaneous power $P_{L}$ absorbed by the load can be easily obtained if $L_{t}$ is known:

$$
=\quad=
$$

Time integration of this power provides the energy $W_{L}$ absorbed by load at a time $t$ :

$$
()=()
$$

The precise value of $L_{t}$ was obtained using Eq. (1) in experiments with a mock-up HV transmission line having the same topology as the real transmission line and connected to a 34 HV resistor that replaced the time-varying load resistance $R_{L}$. For the arrangement used in the present work $L_{t}$ was found to be 9.5

\section{2) Acoustical}

i) Low frequency hydrophone: Teledyne Reson type TC4034 [34], having a usable frequency range from $1 \mathrm{~Hz}$ to $480 \mathrm{kHz}$. The spherical active region of the TC4034 piezoelectric hydrophone is aligned with the center of the electrode gap, in the $\mathrm{x}$ and $\mathrm{z}$ directions, with a separation of $1 \mathrm{~m}$ in the y direction (Fig. 5). This hydrophone is omnidirectional across its bandwidth.

ii) High frequency hydrophone: Precision Acoustics type NH2000 [35], suitable for measurements in the frequency range from $100 \mathrm{kHz}$ to $10 \mathrm{MHz}$. The NH2000 $2 \mathrm{~mm}$ needle PVDF hydrophone is highly directional, particularly for high frequencies, and so great care was taken during its alignment. The active part of this hydrophone, at the tip, was mounted at a separation of $1 \mathrm{~m}$ from the electrode gap (Fig. 5).

iii) Details of hydrophone mounting and operation

The two hydrophones were mounted using supports (see Fig. 5b) and placed at the minimum separation from one another that allowed for the full pressure wave to be captured by each hydrophone before the reflection from the other would be detected and influence the signal. The minimum separation was calculated to be $3.5 \mathrm{~cm}$, and a $4 \mathrm{~cm}$ separation was used. The hydrophones were also separated from the tank walls and surface of the water sufficiently to prevent reflections from these surfaces from interfering with the direct pressure wave received from the HPU. Both hydrophones displayed a strong sensitivity to the powerful electromagnetic noise generated by the pulsed power generator. Due to the conductivity of water, it was not possible to implement proper cable shielding. However, by placing batterypowered oscilloscopes inside Faraday chambers, it was possible to reduce the interference, the hydrophone upset and the recovery time following a strong electromagnetic disturbance.

iv) Software and data analysis: A Mathcad [36] program was developed to analyze the data obtained from the two hydrophones. To help with alignment of the highly directional NH2000 hydrophone, the software was used to test agreement with the TC4034 signal in the overlapping receiving bandwidth (i.e., $100 \mathrm{kHz}$ to $480 \mathrm{kHz}$ ). As neither hydrophone was individually capable to cover the ultrawide spectrum generated by the HPU, the software was used to perform the FFT of the pressure signals and then trim and stitch the two signals in the frequency domain, before performing the inverse FFT to obtain the pressure signal in the time domain corresponding to the entire bandwidth.

\section{Optical}

An ANDOR sCMOS iStar ultra-fast camera [37] was operated with a 3 ns exposure and increased microchannel plate (MCP) gain, to allow for clear images to be obtained. When longer exposure times were used, the very fast motion of the streamers resulted in blurred images. A NIKON Sigma $150 \mathrm{~mm}$ f/2.8 APO Macro EX DG camera lens was coupled to a number of extension tubes (Fotga Auto Focus Macro Extension Tube) to enlarge the image falling on the camera sensor (see Fig. 5a). To protect the camera against electromagnetic interference, it was housed inside a dedicated Faraday chamber, suspended above the water tank. A chamber extension with an optical window lid allowed underwater operation, thus minimizing the distance between the camera lens and the HPU source (Fig. 5.a). 4) Synchronization

The complete synchronization scheme, which only includes the fast electrical and optical diagnostics, is presented in Fig. 6, where the 'Closing switch S1' is switch $S_{l}$ in Fig.1 and the ' $\mathrm{D}$ dot' is a differential electric field sensor measuring the level of electromagnetic 'noise' and also used for triggering and synchronization purposes.

The camera was operated in the External trigger mode with a Pre-trigger option. In this mode two input signals are needed: the first one is applied at $t_{0}$ as a Pre-trigger, preparing the camera sensor, while the second is applied at $t_{2}$ as an External trigger that (after a short time delay) activates the image intensifier to acquire a photo. The spark-gap triggering system is activated at a time $t_{1}$, with $t_{0}<t_{1}<t_{2}$, see Fig. 6 . 


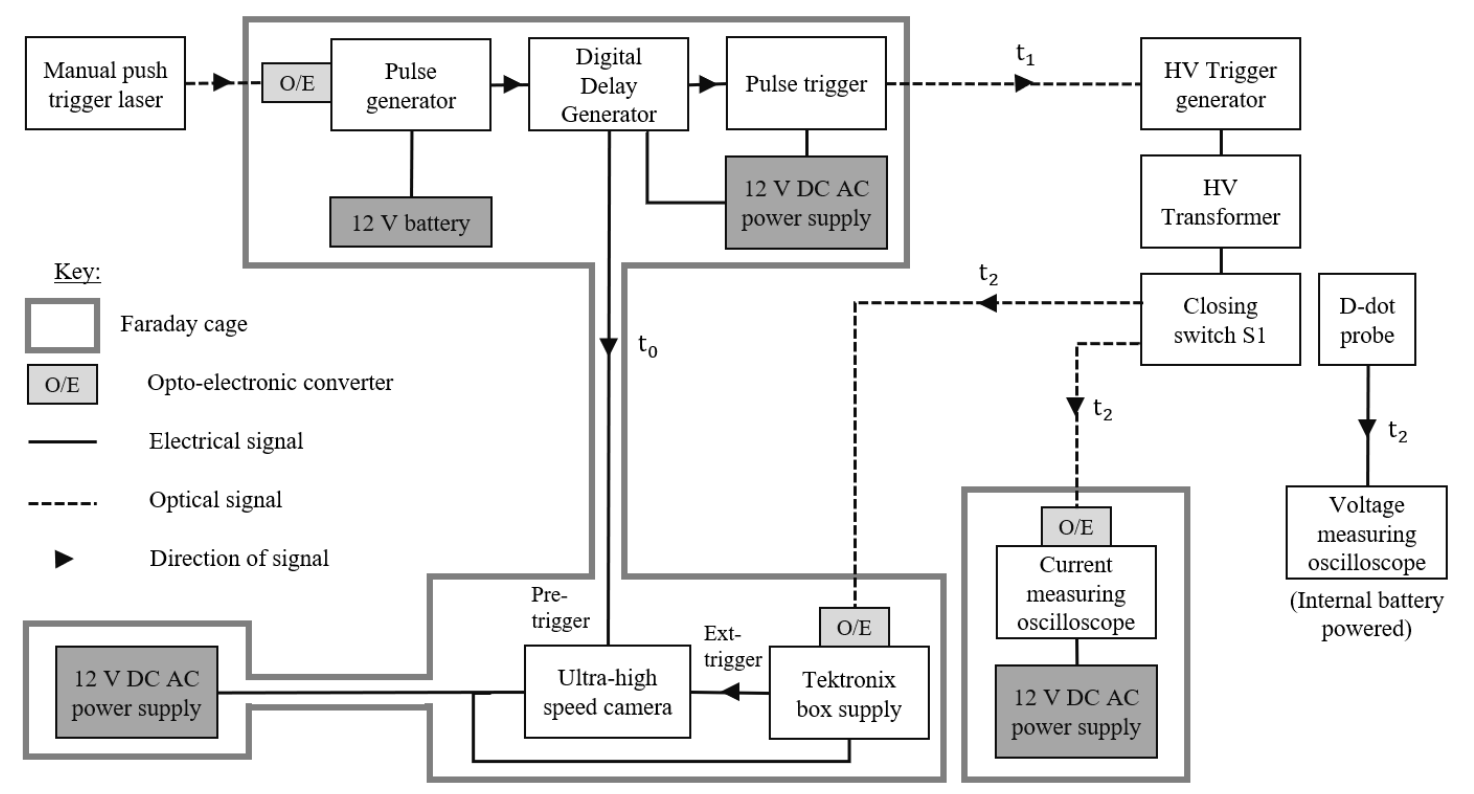

Fig. 6. Schematic of the synchronization scheme.

\section{EXPERIMENTAL RESULTS}

\section{A. Influence of the inter-electrode gap on the peak pressure generated by the HPU source}

The tests reported here were performed with water at a temperature between $20{ }^{\circ} \mathrm{C}$ and $22{ }^{\circ} \mathrm{C}$. The results of a study to find the optimum inter-electrode gap to generate the maximum peak pressure with the present single-shot system are presented in Fig. 7. As the gap increases, the relative peak pressure increases from $84 \%$, corresponding to a gap of $3.1 \mathrm{~mm}$, to $95 \%$ for a $4 \mathrm{~mm}$ gap and finally to $100 \%$ for a gap of $5 \mathrm{~mm}$. The corresponding breakdown voltage is presented in Fig. 8. As the gap increases from $3.1 \mathrm{~mm}$ to $5 \mathrm{~mm}$, the breakdown voltage increases from $92 \mathrm{kV}$, to a value very close to $100 \mathrm{kV}$. Although the $5 \mathrm{~mm}$ gap is apparently the best separation for maximizing pressure, in practice $30 \%$ of shots were unsuccessful ('misfire'), with no voltage breakdown and no substantial pressure generated. For the $4 \mathrm{~mm}$ gap, the experimentally determined chance of misfire was only about $1 \%$, while for the $3.1 \mathrm{~mm}$ gap there were no misfires. All shots presented in this work were performed with a $4 \mathrm{~mm}$ gap.

\section{B. The characteristic pressure pattern generated by the HPU source}

The results of a study to determine the pressure pattern generated at (about) $1 \mathrm{~m}$ distance by the HPU source is presented in Fig. 9, where polar coordinates are used with the maximum corresponding to a peak pressure of $184 \mathrm{kPa}$. Due to reflections by the dome electrode, the pressure pattern has lobes similar to the electromagnetic pattern lobes generated by a dipole antenna.

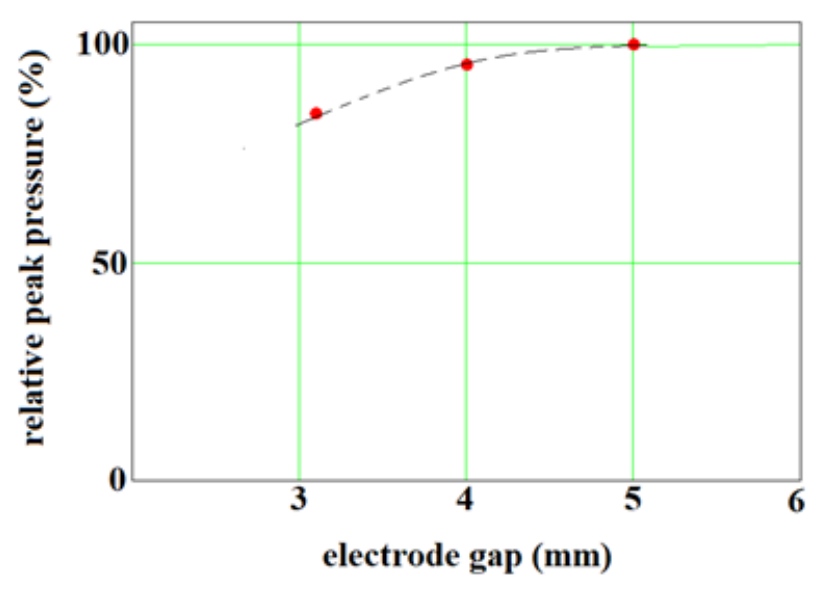

Fig. 7. The variation of the relative peak pressure with electrode gap.

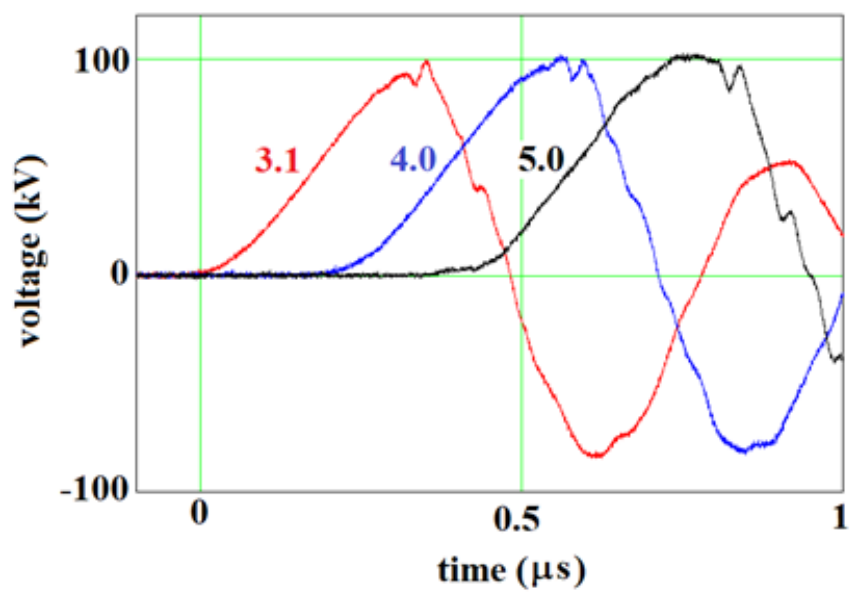

Fig. 8. The time varying voltage corresponding to various inter-electrode gaps (numbers shown in $\mathrm{mm}$ ). To display each breakdown clearly, an artificial delay was introduced between the voltage signals. 


\section{Data from a typical shot}

The electrical data from a typical shot is presented in Fig. 10. The pre-breakdown phase in Fig.10a, represents the time from the beginning of the discharge at $t=0 \mathrm{~ns}$ (closure of $S_{l}$ in Fig. 1) up to the moment the breakdown takes place at $t=330 \mathrm{~ns}$. During this phase, while the voltage increases to its peak, an extremely small displacement current flows through the water, closing the load circuit. This is due to the fact that the rise time ( $10 \%$ to $90 \%)$ of the voltage impulse is only $235 \mathrm{~ns}$, while the relaxation time of the deionised water is much larger i.e., $/=3.54$, where 0 is the permittivity of free space, $r=80$ is the permittivity of water at $20^{\circ} \mathrm{C}$ and $d w=2 \mathrm{~cm}$ is the conductivity of the deionised water used in the tests.

The time variation of the Joule energy absorbed by the source is shown in Fig. 11, with the final energy converging to $W_{L}{ }^{\max }=7.4 \mathrm{~J}$. This energy is larger than the $5 \mathrm{~J}$ stored in $\mathrm{C}_{2}$ (of Fig. 1) when charged to $100 \mathrm{kV}$, showing that even after the breakdown, energy from the primary circuit continues to be pumped into the secondary load circuit.

The optical data in Fig. 12 represents a collection of photos taken from a number of 'identical' (i.e., having the same initial conditions) shots. To easily correlate the streamer dynamics with the electrical data, the time at which each photo was acquired in relation to the electrical signals of Fig. 10 is clearly indicated by letters $a-o$. It is interesting to note the various stages such as: streamer formation and dynamics during the prebreakdown phase, the generation of the luminous central plasma column at breakdown, the slow decay of the streamers and the even slower decay of the plasma column. The first light (Fig. 12b) is detected around $140 \mathrm{~ns}$, when the voltage applied on the pin electrode is $28.5 \mathrm{kV}$ (Fig. 10a). Using the data of Fig. 4c, the corresponding peak electric field is estimated as $285 \mathrm{kV} / \mathrm{cm}$. The electric breakdown at $330 \mathrm{~ns}$ (Fig. 12g) corresponds to $100 \mathrm{kV}$ applied on the pin and a peak electric field of $1 \mathrm{MV} / \mathrm{cm}$.

Fig. 13 presents typical rough acoustical signals recorded with the hydrophones positioned at $1.076 \mathrm{~m}$ distance from the

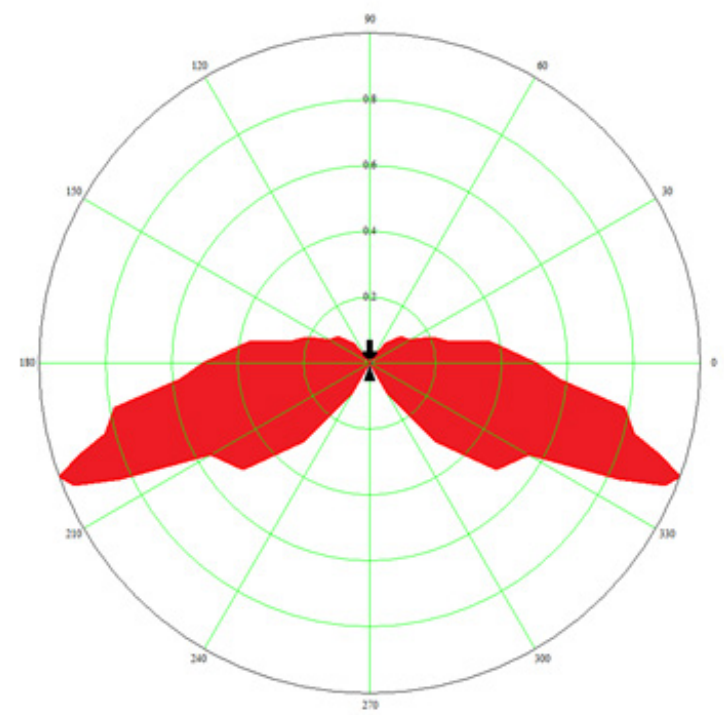

Fig. 9. Pressure pattern generated at $1.076 \mathrm{~m}$ distance by the HPU (in polar coordinates). The position of the electrodes is shown in the center, with 0 degrees corresponding to perpendicular to the electrode axis. The maximum corresponds to a pressure of $184 \mathrm{kPa}$.
HPU source and at 340 degrees (or - 20 degrees), as indicated in Fig. 9. Using the data analysis presented above, the resultant pressure pulse and its corresponding FFT are presented in Figs. 14 and 15, respectively. The maximum pressure recorded was $184 \mathrm{kPa}(225 \mathrm{~dB}$ re 1

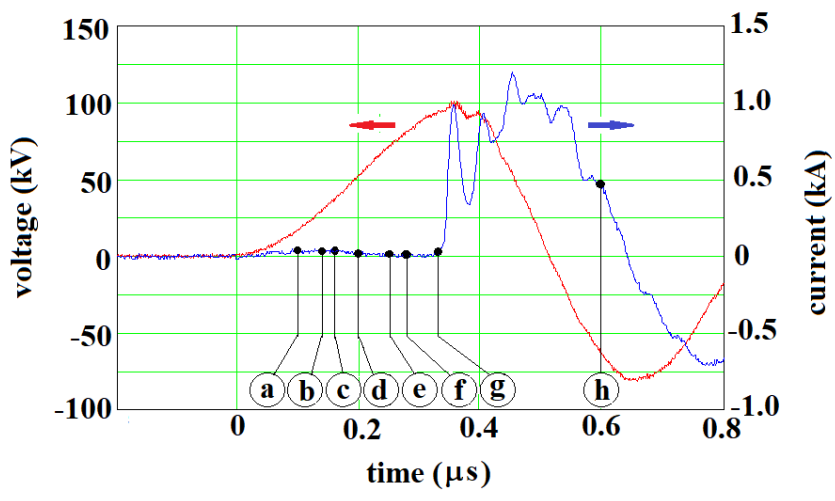

a)

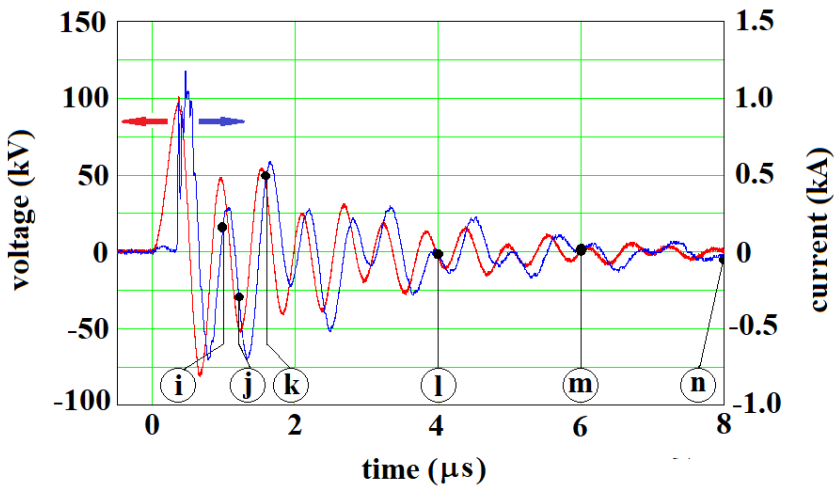

b)

Fig. 10. Voltage and current signals during a typical shot.

a) the beginning of the prebreakdown phase is from $t=0 \mathrm{~ns}$ (closure of $S_{I}$ in Fig. 1) up to the moment the breakdown takes place at $t=330 \mathrm{~ns}$. The rise time $(10 \%$ to $90 \%)$ of the voltage impulse is $235 \mathrm{~ns}$, while the displacement current is negligible $b$ ) the total duration of the discharge is about 8 The letters are corresponding to those in Fig. 12.

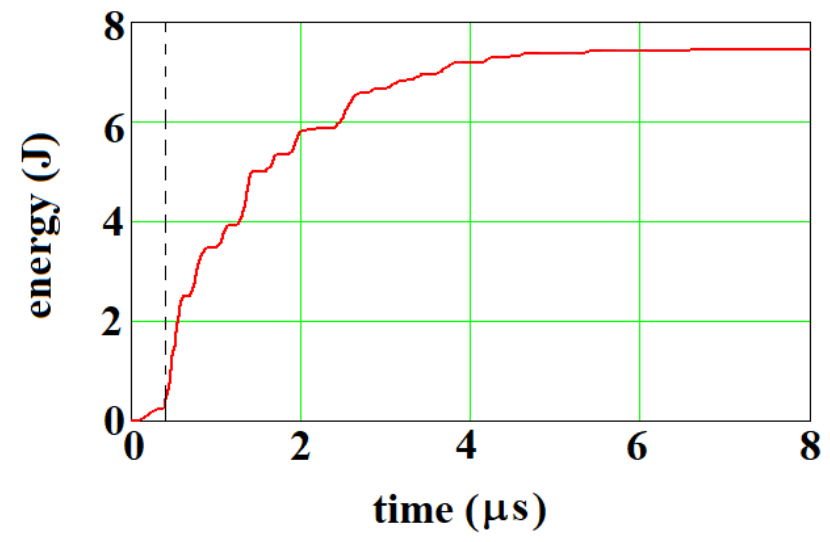

Fig. 11. Time dependence of the Joule energy deposited in the load. The vertical dotted line represents the breakdown time i.e., the end of the prebreakdown phase. The maximum energy reached is $7.4 \mathrm{~J}$. 


\section{Efficiency of energy conversion}

The acoustic energy carried at a time $t$ by the pressure pulse generated by the HPU can be calculated based on the data of Fig. 9 and Fig. 14. Consider that the normalized pressure data $P_{k}$ of Fig. 9 has been collected at $N$ different angles $k$, with $k=1, \ldots, N$. In this case the acoustic energy $W_{a}$ can be calculated as [16]:

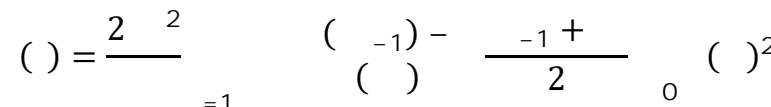

where $r=1.076 \mathrm{~m}$ is the radius of the sphere on which the measurement is performed, $=10^{3} \mathrm{Kg} / \mathrm{m}^{3}$ is the mass density of water, $v=1480 \mathrm{~m} / \mathrm{s}$ is the speed of sound in water; the area of a spherical segment $A_{k}$ was calculated using spherical coordinates as:

$$
=
$$

$$
=2
$$

and finally, the time integral is performed using the pressure pulse $p(t)$ of Fig. 14. The result of the calculations is presented in Fig. 16 and shows the maximum acoustic energy carried by the pressure pulse is $W_{a}^{\max }=62 \mathrm{~mJ}$. The energy efficiency is therefore $=-100=0.8 \%$.

\section{E. Operation of the HPU with freshwater}

A few tentative shots were performed with the acrylic tube filled with freshwater having a conductivity $f_{w}=500$, with $/=14.2$ being smaller than the voltage impulse rise time of $225 \mathrm{~ns}$. The freshwater experiments used a different pin electrode and support assembly (not shown), that does not leave any metal surface uncovered, apart from the tip of the pin and the small exposed area on dome. For these tests the TC4034 hydrophone was placed $1 \mathrm{~m}$ distance from source and at 0 degrees (see Fig. 9). The results are presented in Figs. 17 and 18 and show a lower peak voltage $(80 \mathrm{kV})$ and a pressure of only $78 \mathrm{kPa}$, representing $89 \%$ of the value generated by the source at the same position when using deionized water. The lower efficiency is due to the conduction current reaching $280 \mathrm{~A}$ during the pre-breakdown phase, which corresponds to an amount of Joule energy being used less efficiently.

\section{CONCLUSIONS AND THE WAY AHEAD}

A supersonic underwater HPU was demonstrated to generate a peak pressure of $184 \mathrm{kPa}(225 \mathrm{~dB}$ re 1 $\mathrm{m}$ when operated in deionized water and $78 \mathrm{kPa}$ in freshwater. The HPU is only using $7.4 \mathrm{~J}$ of electrical energy and therefore can be made very compact and at least in principle, by changing the HV charger, the closing switch and the electrodes, it can be operated at a very high PRF. The pressure profile of the source was found to display a resemblance to a far field dipole antenna radiation pattern. Using an ultrahigh speed camera, an optical study revealed highly complex inter-electrode plasma dynamics. When operated with deionized water, the efficiency
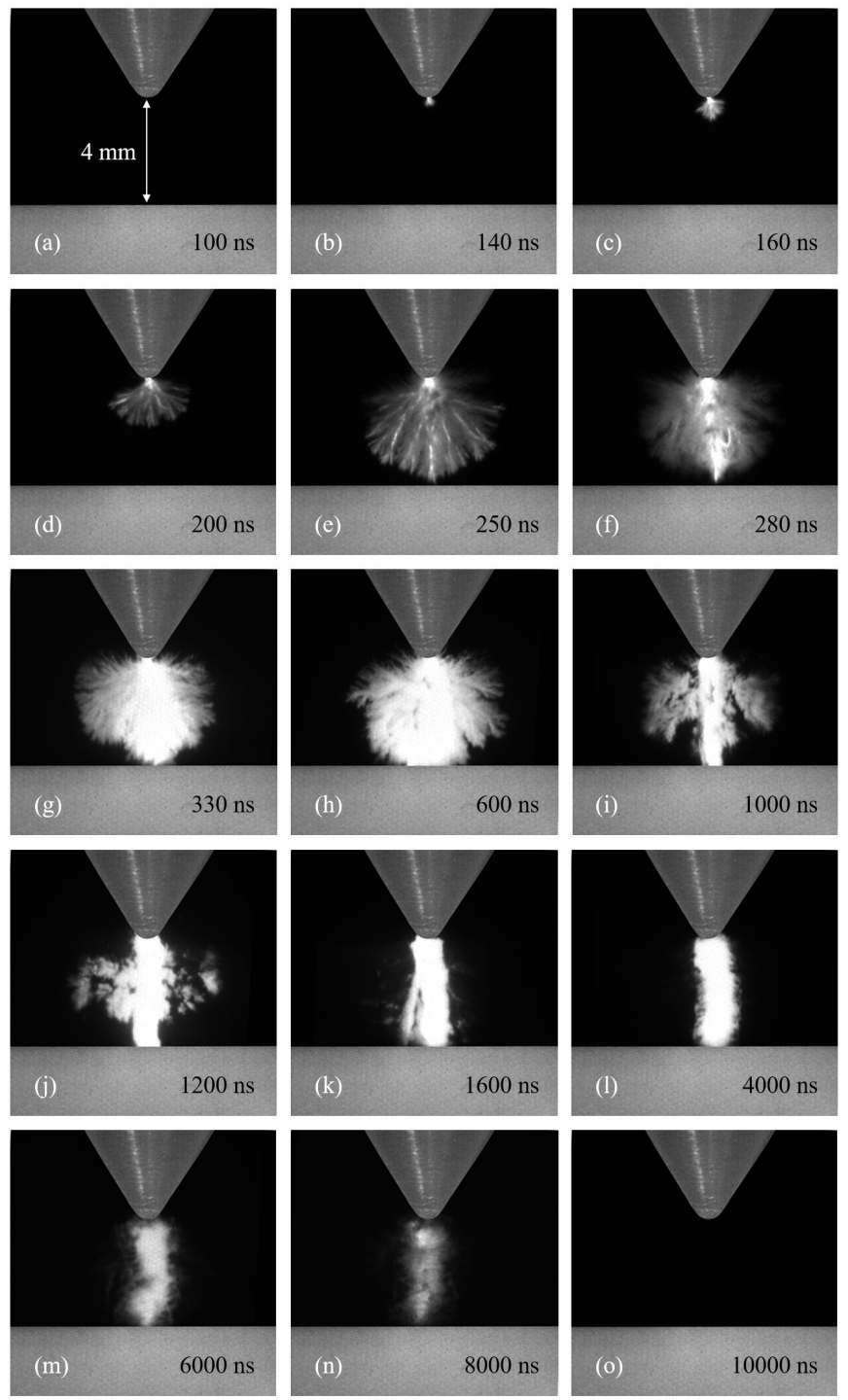

Fig. 12. Ultrahigh speed camera photos taken during 'identical' HPU shots with an exposure time of $3 \mathrm{~ns}$. The time origin is from the beginning of the discharge i.e., the closure of $S_{l}$ in Fig 1. The letters are corresponding to those in Fig. 10.

of energy conversion from electrical to acoustic was estimated to be $0.8 \%$.

Plans for future include a detailed analysis of plasma streamers using the Schlieren technique and operation of the HPU source at a PRF of $1 \mathrm{kHz}$. 
MS\#
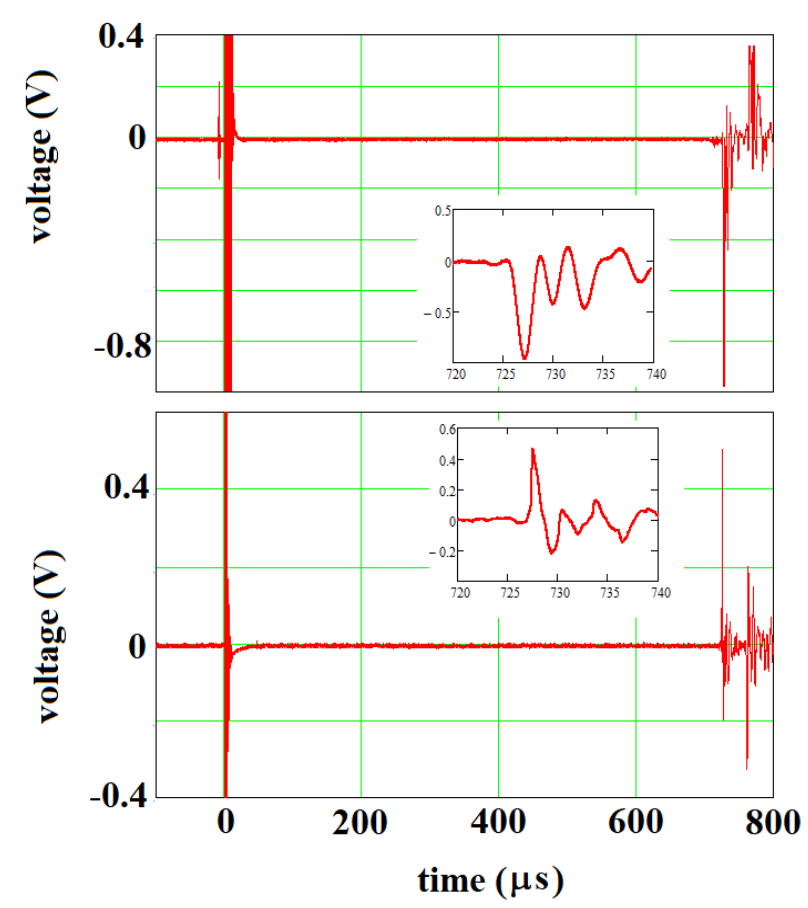

Fig. 13. Pressure signals generated by the two hydrophones, as recorded on oscilloscopes. Upper trace: the TC4034 hydrophone output is negative and without use of a preamplifier. Lower trace: the NH2000 hydrophone output is positive and uses a preamplifier. Note the early, large signal due to the electromagnetic interference at $t=0$ -gap $S_{I}$ in Fig. 1 is closing. For a short time both hydrophones are upset. The main pressure pulse arrives at the hydrophones after 727

by the sound of $1.076 \mathrm{~m}$. The inserts present details of the pressure pulses recorded.

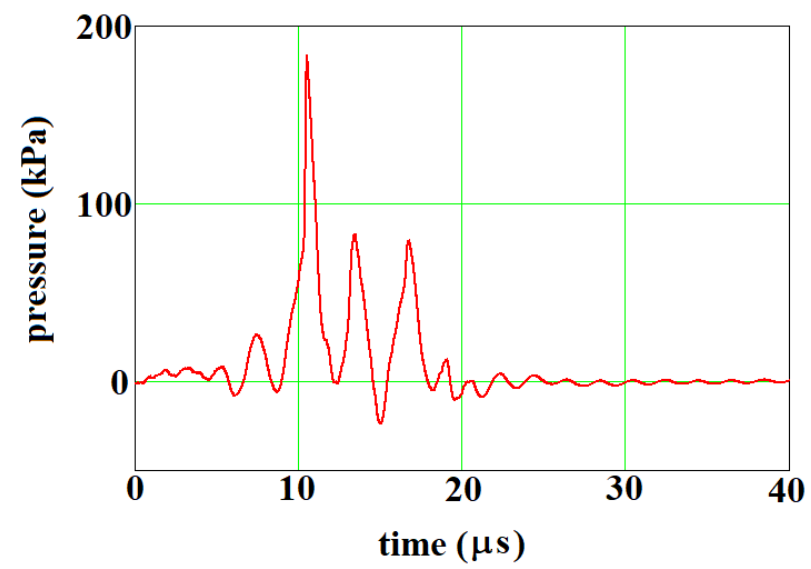

Fig. 14. Pressure pulse obtained from data presented in Fig. 13 using the analysis technique detailed in text. The pressure at the first peak is $184 \mathrm{kPa}$. The time origin corresponds to 715 $S_{l}$ of Fig. 1.

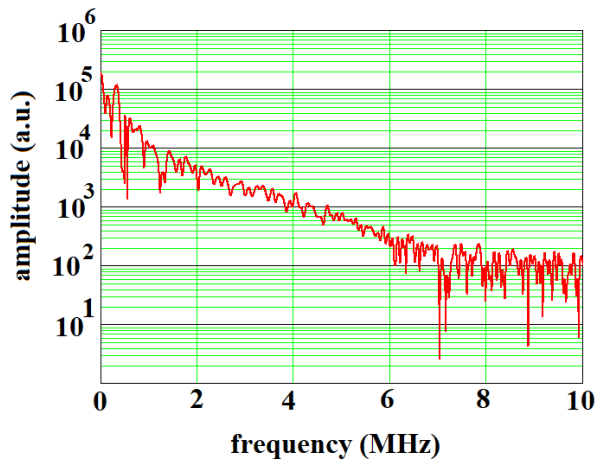

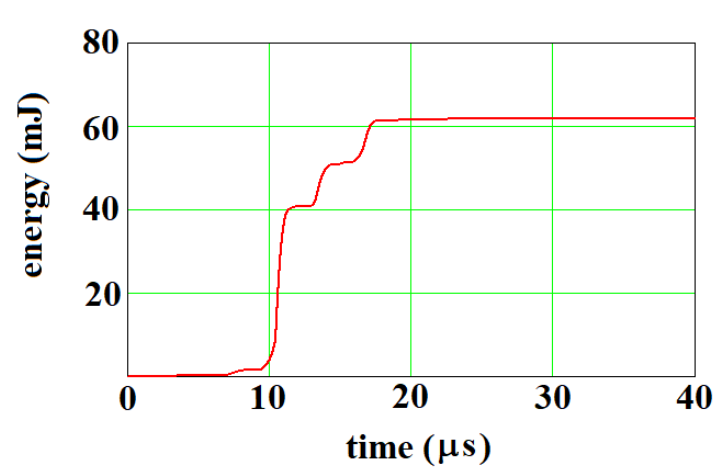

Fig. 16. Time dependence of acoustic energy carried by the pressure pulse of Fig. 14. The total acoustic energy is $62 \mathrm{~mJ}$. The acoustic energy produced by pre-breakdown phenomena can clearly be identified as the small shoulder prior to the sharp rise corresponding to breakdown.

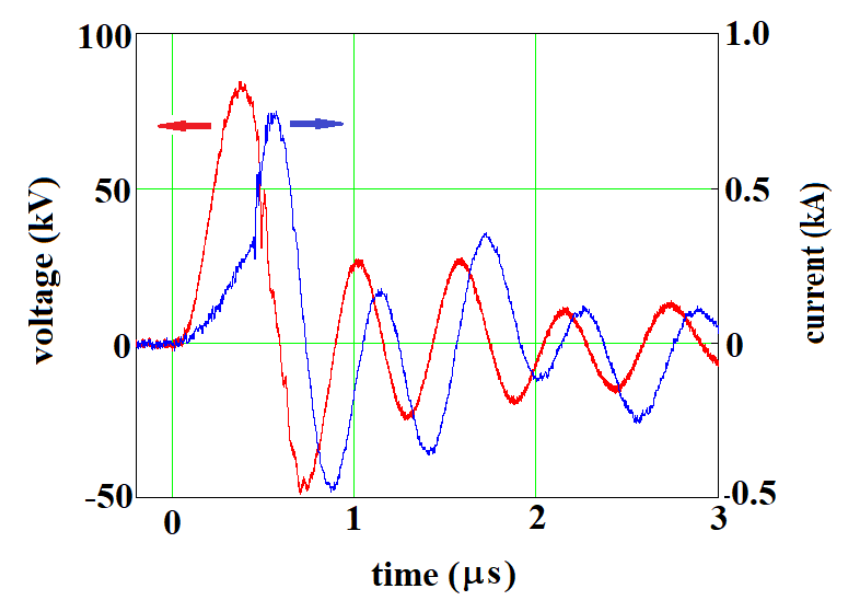

Fig. 17. Voltage and current signals during a typical shot with the HPU functioning with freshwater. During the pre-breakdown phase, the conduction current reaches $0.28 \mathrm{kA}$. Due to this large value, the voltage is only able to reach about $80 \mathrm{kV}$.

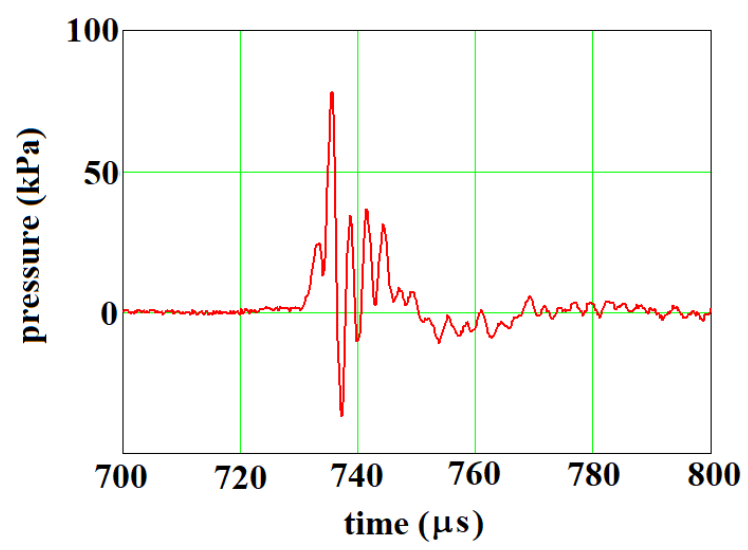

Fig. 18. Pressure pulse measured with the TC4034 hydrophone at $1 \mathrm{~m}$ from the HPU source functioning with freshwater. The peak pressure is $78 \mathrm{kPa}$.

Fig. 15. FFT of the pressure pulse presented in Fig. 14. 


\section{REFERENCES}

[1] Bmax, accessed on 2020 [Online], Available https://www.bmax.com/technology/electro-hydraulic-forming/

[2] J. Hofmann and Th. H.G.G. Weise "Pulsed Power Technologies for Commercial Material Reduction and Crushing Applications", in Proc. 11th IEEE Int. Pulsed Power Conf., Baltimore, 1997, pp 203-207

[3] K. J. Touryan, L. A. Touryan, and J. W. Benze, "An innovative use of pulsed power technology for separation of minerals from ores," in Proc. 8th IEEE Int. Pulsed Power Conf., San Diego, 1991, pp. 90-93.

[4] Geun-Hie Rim, Chu-Hyun Cho, Hong-Sik Lee, E.P. Pavlov, "An electricblast system for rock fragmentation", in Proc. 12th IEEE Int. Pulsed Power Conf., Monterey, 1999, pp. 165-168

[5] S. Pronko, G. Schofield, M. Hamelin and F. Kitzinger "Megajoule Pulsed Power Experiments for Plasma Blasting Mining Applications", in Proc. 9th IEEE Int. Pulsed Power Conf., Albuquerque, 1993, pp. 11-18.

[6] I.V. Lisitsyn, H. Inoue, S. Katsuki, H. Akiyama, I. Nishizawa "Drilling and demolition of rocks by pulsed power, in Proc. 12th IEEE Int. Pulsed Power Conf., Monterey, 1999, pp. 169-172

[7] S. Boev, N. Yavorovsky,"'Electropulse water treatment", in Proc. 12th IEEE Int. Pulsed Power Conf., Monterey 1999, pp.181-184

[8] M. S. Mazzola, M. G. Grothaus, ,M.Walch, and J. Jones-Meehan, "New electrical control methods to prevent power plant fouling," in Proc. 10th IEEE Int. Pulsed Power Conf., Albuquerque, 1995, pp. 34-39.

[9] H.Akiyama, S. Sakai, T. Sakugawa and T. Namihira, "Environmental Applications of Repetitive Pulsed Power", IEEE Trans. Dielectric. Electr..Ins., Vol. 14, No. 4; 2007, pp. 825-833

[10] Ushakov V Y, Klimkin V F and Korobeynikov S M, 2007 "Impulse Breakdown of Liquids" (Berlin: Springer)

[11] J. W. Mackersie, I. V. Timoshkin, and S. J. MacGregor, "Generation of high-power ultrasound by spark discharges in water", IEEE Trans. Plasma Science, Vol. 33, No. 5, 2005 pp. 1715-1724

[12] D. D. Caulfield, "Predicting sonic pulse shapes of underwater spark discharges," Deep-Sea Res. Oceanogr. Abstr. Vol. 9, 1962, pp. 339-348

[13] A. H. Olson and S. P. Sutton, "The physical mechanisms leading to electrical breakdown in underwater arc sound sources,"' J. Acoust. Soc. Am.

Vol. 94, 1993, pp. 2226-2231

[14] I V Timoshkin, R A Fouracre, M J Given and S J MacGregor, "Hydrodynamic modelling of transient cavities in fluids generated by high voltage spark discharges", J. Phys. D: Appl. Phys. Vol. 39, 2006, pp. 48084817

[15] S. Buogo and G. B. Cannelli, "Implosion of an underwater spark-generated bubble and acoustic energy evaluation using the Rayleigh model,"

J. Acoust. Soc. Amer., vol. 111, pp. 2594-2600, 2002.

[16] S. Buogo and J. Plocek, "Efficiency of energy conversion in underwater spark discharges and associated bubble oscillations: experimental results", Acta Acustica, Vol. 95, 2009, pp. 46 - 59

[17] G Touya, T Reess, L P'ecastaing, A Gibert and P Domens, "Development of subsonic electrical discharges in water and measurements of the associated pressure waves", J. Phys. D: Appl. Phys., Vol. 39, 2006, pp. 5236-5244

[18] J. F. Kolb, R. P. Joshi, S. Xiao and K. H. Schoenbach, "Streamers in water and other dielectric liquids", J. Phys. D: Appl. Phys. Vol. 41, 2008, 234007

[19] I Marinov, O Guaitella, A Rousseau and S M Starikovskaia, "Modes of underwater discharge propagation in a series of nanosecond successive pulses", J. Phys. D: Appl. Phys. Vol. 46 2013, 464013 (9pp)

[20] I. Marinov, S. Starikovskaia and A. Rousseau, "Dynamics of plasma evolution in a nanosecond underwater discharge", J. Phys. D: Appl. Phys. Vol. 47, 2014, 224017 (10pp)

damage of tissues induced by focused shock waves. IEEE Trans. on Plasma Science, Vol. 32, 2004, pp. 1609-1613.

[22] M. Bourlion, P. Dancer, F. Lacoste, J.-L. Mestas, D. Cathignol "Design and characterization of a shock wave generator using canalized electrical discharge: Application to lithotripsy", Rev. Sci. Instr., Vol. 65, 1994, pp. 23562363.

[23] Da-Wen Sun, Emerging Technologies for Food Processing (2nd Edition), Academic Press, 2014

[24] Loughborough University Internal Report, 2016 (unpublished)

[25] General Atomics accessed on 2020 [Online]. Available: http://www.ga.com/capacitors

[26] R.E. Beverly III \& Associate accessed on 2020 [Online]. Available: http://www.reb3.com/products.php

[27] "A $1 \mathrm{kHz}, 120 \mathrm{kV}$ magnetic core transformer-based generator", to be submitted to IEEE Trans. Plasma Science
[28] MES, accessed on 2020 [Online]. Available: http://www.manzelectronic.de/

[29] CST, accessed on 2020. [Online]. Available https://www.cst.com/Products [30] EssexX-Ray, accessed on 2020 [Online] https://www.essexxray.com/highvoltage-cable-shielded-unshielded-core/

[31] Teledyne Reynolds UK, accessed on 2020 [Online]. Available: http://www.teledynereynolds.co.uk/products/high-voltage-wire-cable

[32] North Star, accessed on 2020 [Online]. Available: https://www.highvoltageprobes.com/products/high-voltage-probes/

[33] Pearson Electronics, accessed on 2020 [Online]. Available: https://www.pearsonelectronics.com/products/wideband-current-monitors

[34] Teledyne Marine, accessed on 2020 [Online]. Available: http://www.teledynemarine.com/reson-tc-4034/?BrandID=17

[35] Precision Acoustics, accessed on 2020 [Online]. Available: https://www.acoustics.co.uk/pal/wp-content/uploads/2016/05/nh2000-2.0mm-needle-hydrophone-tds.pdf

[36] PTC Mathcad, accessed on 2020 [Online]. Available: https://www.mathcad.com/en/try-and-buy/free-trial

[37] Andor, accessed on 2020 [Online]. Available: https://andor.oxinst.com/products/istar-intensifiedcameras?gclid=EAIaIQobChMIqZCPwd36AIVAdd3Ch2dxA0fEAAYASAAEgIgIPD_BwE 


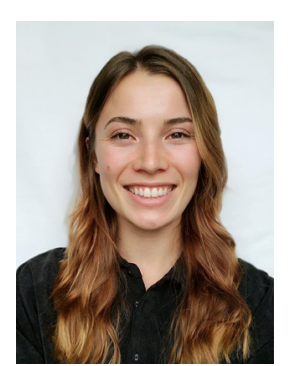

Jessica M. Stobbs (Student Member, IEEE) is a third year $\mathrm{PhD}$ student working under the supervision of B. M. Novac at Loughborough University in the Plasma and Pulsed Power Group. Her research employs a combination of electrical, acoustic, and optical diagnostics to study nanosecond electrical breakdown of water for generating ultrasound. She received an M.Sc. in Physics in 2018 from Loughborough University.

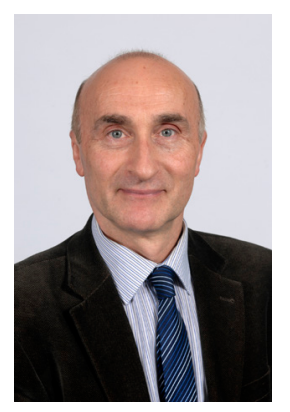

Bucur M. Novac (M'06 - SM'08) received the M.Sc. and Ph.D. degrees in 1977 and 1989, respectively, both from the University of Bucharest. He joined the Loughborough University, UK in 1998 and is currently Professor of Pulsed Power. His research interests include compact and repetitive high-power systems, explosively and electromagnetically driven magnetic flux compression generators and their applications, electromagnetic launchers, ultrafast magneto and electro-optic sensors and 2-D modeling of pulsedpower systems. He has co-authored two books on explosive pulsed power and has published more than 200 refereed papers and conference contributions.

$\mathrm{He}$ is a member of the International Steering Committees for both the MEGAGAUSS Conferences and for the Euro-Asian Pulsed Power Conferences. Prof. Novac was a voting member of the Pulsed Power Science \& Technology Committee in the IEEE Nuclear and Plasma Science Society and a member of the organizing committee for the IEEE International Power Modulator and High Voltage Conference as well as co-chairman of the UK Pulsed Power Symposia.

Prof. Novac is a Fellow of the Royal Academy of Engineering, a Chartered Engineer and a Fellow of The Institution of Engineering and Technology, UK.

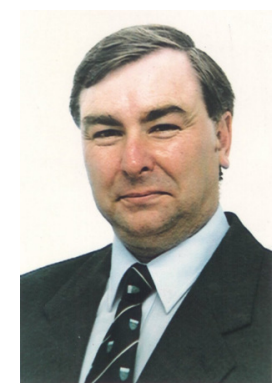

Peter Senior (M'16) received an Honours Degree in Physics with Electronics from Leicester University. $\mathrm{He}$ is a member of the Institute of Physics and a Chartered Physicist. He began his career in the Electronic and Electrical Engineering Department at Loughborough University researching Ultrasonic Nondestructive Evaluation, extending into Nonlinear (Finite Amplitude) Acoustics. He was one of the founder members of the Pulsed Power Research Group (1986). He has worked on Propellant and Explosive Pulsed MHD Generators, and also produced systems to support a Flux Compressor Programme. Other work has included High Efficiency Launchers and the Electromagnetic Protection of Armoured Vehicles. He has produced a number of Transportable High Energy, High Power Systems, varying in size between fitting into a van, and up to two ISO Containers, supplied by diesel generators. This has required expertise in the Health and Safety Aspects of integrating Pulsed Power systems with the equipment of sponsoring and collaborating bodies.

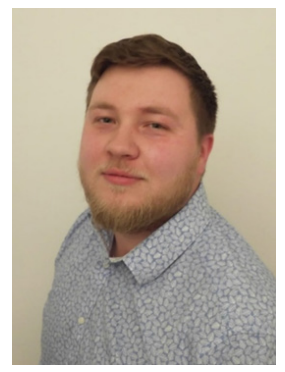

Matthew Woodyard (Student Member, IEEE) received the BEng degree from Loughborough University, UK in 2015 . He is currently a PhD researcher with the Plasma and Pulsed Power Group, Loughborough University, UK. His research interests include Tesla transformer driven pulsedpower generation and large volume Pulsed Electric Fields (PEF) applications in water.

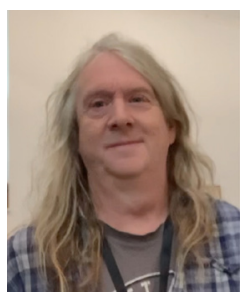

Paul Lepper is a Reader for Under Water Acoustics and Bioacoustics at Loughborough University, UK, with nearly 30 years' experience of studies in physical and biological aspects of underwater acoustics. He received his Ph.D. degrees in 2000 from Loughborough University in Parametric Sonar development. From 2000-2002 he was a visiting Scientist at Scripps Institute, UCSD, San Diego, USA, returning to Wolfson School, Loughborough University, in 2002 to his current role as head of underwater research. He has over 200 published papers in the area of underwater acoustics and bioacoustics. $\mathrm{He}$ is a Fellow of the Higher Education Academy and Deputy Associate Dean of Enterprise for Wolfson School, Vice-President - International for the Institute of Acoustics (UK) and General Secretary of the European Acoustics Association (EAA). He has been on the organizing committees on numerous national and international conferences including ECUA (2012), OCEANOISE (2015), Effects of Aquatic Noise AN2019 (2019/2022), INTERNOISE (2022), etc, and has chaired / co-chaired various international conferences in areas of underwater acoustics, bioacoustics and underwater noise. 